\title{
Proses Menulis Artikel Ilmiah: Dari Ide Hingga Publikasi
}

\author{
Muhammad Farid \\ Universitas Negeri Makassar, Indonesia; \\ National Kaohsiung University of Applied Sciences, Taiwan \\ Email: muhammadfarid@unm.ac.id
}

\author{
Ismail Suardi Wekke \\ Sekolah Tinggi Agama Islam Negeri (STAIN) Sorong, Indonesia; \\ University College of Yayasan Pahang, Malaysia \\ Email: ismail@stain-sorong.ac.id
}

\begin{abstract}
Generating a scientific article is a process from finding ideas to publication in order to be accessible to the public. A student is not sufficiently stalled to produce a paper at the end of his studies or the researcher ends up being a research report, but is expected to publish it in the form of scientific articles through conference and or scientific journals. Identifying the writing process, writing format and information about scientific publications will help facilitate the publication of the intended conferences or journals.
\end{abstract}

Keywords: writing; scientific article; ideas process; publication.

Orang boleh pandai setinggi langit, tapi selama ia tidak menulis, ia akan hilang di dalam masyarakat dan dari sejarah. Menulis adalah bekerja untuk keabadian, Toer (1990).

\section{Pengantar}

Seorang mahasiswa atau peneliti yang telah menghasilkan karya ilmiah dan terpublikasi melalui seminar internasional atau jurnal akan menjadi penanda sumbangsih bagi kemajuan ilmu pengetahuan. Tanpa itu, maka hanya akan terbaca dalam lingkup yang terbatas, atau bahkan justru tidak diketahui publik sama sekali. Selain memberikan kesempatan kepada publik untuk membaca dan memahami lebih lanjut tentang ide dan hasil penelitiannya, juga berkonstribusi terhadap pengembangan ilmu pengetahuan dan teknologi pada bidang masing-masing.

Di akhir studinya, seorang mahasiswa sesuai jenjang pendidikan yang ditempuh diwajibkan menghasilkan karya tulis ilmiah sebagai salah satu syarat untuk penyelesaian studinya. Namun setelah selesai studi sebagian besar tidak lagi melanjutkan menulis artikel, kecuali bila mereka 
memilih menjadi peneliti atau tenaga pengajar di perguruan tinggi. Walaupun demikian, kemampuan yang sudah dicapai akan menjadi kesempatan dalam menggunakan nalar dan selanjutnya akan menjadi keterampilan yang dapat digunakan dalam lingkup pekerjaan. Walaupun itu tidak berhubungan langsung dengan penelitian, namun dapat menjadi sebuah pengalaman belajar. Pada akhirnya dapat digunakan dalam kesempatan yang lebih luas. Pada saatnya, secara perlahan perguruan tinggi Indonesia menerapkan standar kewajiban untuk memublikasikan tugas akhir sebagai persyaratan kelulusan.

Seorang dosen atau peneliti, publikasi menjadi bagian syarat penilaian kinerja dan juga kenaikan jabatan fungsional/pangkat harus menghasilkan publikasi ilmiah dengan kriteria dan perhitungan angka kredit disesuaikan dengan jabatan fungsional yang akan diraih. Namun perlu dicatat secara khusus, penulisan dan publikasi bukanlah dilakukan karena urusan pangkat semata. Lebih dari itu, melampaui tujuan administratif yaitu dalam rangka pengembangan ilmu pengetahuan dan juga kontribusi bagi masyarakat. Maka, ketika melakukan publikasi dilakukan secara tidak langsung akan menjadi ikhtiar dalam menyumbang bagi kemajuan ilmu pengetahuan. Dampaknya, sang penulis akan naik pangkat. Bukan sebaliknya, publikasi diniatkan untuk naik pangkat. Sehingga setelah kenaikan pangkat diperoleh, publikasi ilmiah juga terhenti. Nanti pada periode kenaikan pangkat berikutnya, aktivitas publikasi kembali dilakukan.

Penulisan karya ilmiah tidak cukup berhenti sampai menghasilkan sebuah tesis saja, namun bagaimana bisa terpublikasi melalui seminar atau jurnal ilmiah (Lindsey, 1978). Mahasiswa, dosen, dan peneliti semuanya memerlukan untuk registrasi kecendekiaan mereka. Dengan melakukan publikasi pula, maka penulis sudah memiliki otonomi keilmuan dalam topik tertentu (Chase, 1970). Tanpa publikasi, maka penelitian belum terbaca di publik. Hanya akan menjadi data bagi peneliti. Selanjutnya, bagaimana proses dari ide, menulis karya ilmiah hingga bisa dipblikasikan? Pertanyaan berikutnya, apakah seseorang menulis artikel karena dorongan untuk memenuhi syarat akademik tertentu? atau memang karena passion dan mendedikasikan dirinya untuk kemajuan ilmu pengetahuan dan teknologi.

\section{Mengembangkan Ide}

Ide biasanya didapatkan dari berbagai sumber, antara lain dengan: membaca buku, membaca jurnal ilmiah, berdiskusi, menghadiri seminar, mengamati fenomena di masyarakat, atau berasal dari sumber lainnya. Diskusi bersama pembimbing akan memberi kesempatan kepada mahasiswa untuk mendapatkan ide. Pembimbing akan memberikan alternatif, apakah 
sesuai dengan topik yang diminati mahasiswa atau mengarahkan sesuai dengan topik riset yang sementara dikerjakan. Sementara bagi peneliti atau dosen, diskusi dengan kolega akan menjadi kesempatan dalam mengembangkan sebuah ide. Maka, menghadiri seminar atau konferensi dalam rangka mendapatkan kesempatan untuk berdiskusi dengan kolega yang tidak berada dalam institusi yang sama. Bahkan kesempatan ini bisa menjadi lintas perguruan tinggi atau lintas negara. Niatan awal untuk menghadiri seminar atau konferensi perlu dibangun atas keinginan untuk mendapatkan kesempatan dalam mengkomunikasikan temuan-temuan penelitian mutakhir sekaligus bertemu dengan kolega dari pelbagai instansi sehingga mendapatkan review awal dalam meneruskan penelitian yang sementara dilaksanakan.

Seorang penulis dapat menghubungkan aktivitas atau pengalaman pribadinya yang relevan dengan topik dan bidang penelitian yang digeluti (Lester, \& Lester, 2012). Bila mendapatkan ide, perlu segera dituliskan. Entah di kertas, buku catatan atau media lainnya agar bisa diteruskan bila telah punya waktu untuk memulai proses penulisan. Hal ini dibutuhkan untuk menghindari hilangnya ide saat itu. Ide sangat terkait dengan momentum, sehingga pada kesempatan pertamalah ide yang muncul itu perlu diabadaikan. Seiring dengan berlalunya momentum, maka ide juga akan segera hilang begitu saja. Catatan kecil yang sudah ditorehkan akan menjadi pengingat dan kemudian dapat ditindaklanjuti menjadi sebuah proses awal penelitian. Bisa juga dengan media sosial. Ide yang terlintas akan dapat ditelusuri kembali jika sudah diabadikan dalam tulisan-tulisan singkat di platform media sosial.

Hal yang menghambat dalam memulai menulis, bila berpikir bahwa ide tersebut harus brilliant atau akan mengguncangkan dunia, barulah menggerakkan kita untuk berkarya. Menulis dapat dimulai dari hal yang paling sederhana sekalipun, tidak perlu menunggu sampai sempurna, biarlah ide tersebut berproses dan bertahap. Apabila tidak bisa diselesaikan pada penelitian pertama, nanti bisa dilanjutkan pada proses penelitian berikutnya atau biarlah karya kita menemukan takdirnya (Farid, 2017a). Justru berkarya justru perlu ditulis dengan sebuah ide yang biasa-biasa saja. Bahkan terkait dengan kehidupan pribadi dalam aktivitas sehari-hari. Hanya saja dikaitkan dengan analisis ilmiah sehingga dapat dijadikan sebagai sebuah artikel untuk publikasi. Sebagaimana Newton mengawali penemuan teori gravitasi yang bahkan hanya karena duduk di bawah pohon apel. Setelah itu observasi dilakukan dan pada akhirnya memberikan penjelasan tentang gravitasi (Jensen Schau, \& Muñiz Jr, 2006; Fara, 1999; McKie, \& De Beer, 1951; Gleick, \& Alexanderson, 2005). Kemudian dalam proses berikutnya, menjadi pertanyaan sehingga dilakukan penelusuran secara ilmiah. Begitu pula dapat menggunakan pengarsipan online sehingga sejak awal penulis sudah mendapatkan perlindungan hak cipta (Wekke, 2019a). 


\section{Proses Penulisan Artikel}

Untuk menghasilkan sebuah karya ilmiah haruslah memenuhi kaidah penulisan yang lazim dalam masyarakat akademik. Laplante (2018) mengemukakan proses penulisan dalam lima tahap, yaitu: brainstorming, drafting, revising, editing dan publishing.

Pertama, brainstorming. Proses ini umumnya disebut dengan pre-writing, merupakan pencatatan ide di atas kertas. Dalam penulisan kreatif, proses ini sangat bebas bentuk dan bisa mencakup gagasan apapun, ibaratnya apa yang ada dalam pikiran dapat dituangkan dalam selembar kertas. Menulis merupakan proses yang bertahap dan berkelanjutan. Tidak bisa hanya sekali langsung selesai (Rohman, 1965). Dalam menulis, bagian terpenting yang sudah perlu diidentifikasi adalah soal ide (Kellogg, 1990). Kedua, drafting. Proses ini dimulai sengan melengkapi kalimat secara utuh, paragraf dan sub topik yang dilakukan saat proses brainstorming. Selanjutnya dengan membuat penghubung di antara kalimat dan sub topik. Pada proses ini biarlah ide mengalir, abaikan sementara tata bahasa, walaupun pada layar komputer anda telah menunjukkan kesalahan pengejaan. Bagian ini adalah melengkapi keseluruhan unsur dan komposisi artikel. Sehingga pada tahapan selanjutnya sudah bisa menuju ke proses penyuntingan (Clemens, \& Graham, 2007)

Ketiga, revising. Setelah menghasilkan tulisan lengkap, selanjutnya membuat tulisan yang baik melalui revisi. Laplante (2018) menyarankan untuk menimal melibatkan dua orang. Satu orang yang memahami secara teknis, yaitu orang yang memahami tentang bidang tersebut. Sedangkan yang lainnya secara non teknis, yang berfungsi untuk menemukan kesalahan logika dari tulisan tersebut. Sampai kapan mengakhiri tahapan revisi? Bila batasan waktu yang telah ditentukan telah tiba.

Keempat, editing. Tahapan ini bisa menggunakan beberapa cara. Setelah melakukannya sendiri, kemudian meminta bantuan kolega. Terakhir, menggunakan jasa editor profesional. Hal-hal yang perlu dilakukan dilakukan selama proses ini, perhatikan tata bahasa dan format yang telah ditetapkan sebagaimana dalam author guidlines. Namun ini bukan satu-satunya reomendasi. Sebagai proses akademik, tanpa kehadiran penutur asli bukan sebuah masalah. Ini semata-mata hanya soal teknis belaka (Gosden, 1995). Ketika terlihat bahwa ada proses akademik, maka bisa saja melalui tahapan ini tanpa bantuan native speaker.

Terakhir, publishing. Proses ini akhir dari sebuah tulisan dan dimaksudkan bahwa dokumen kita dapat diakses oleh publik. Dokumen yang sementara dalam proses review, dapat disimpan di pengarsipan daring seperti INAR-Xiv. Sebelum mempublikasikan dokumen tersebut, haruslah 
yakin bahwa inilah final version dan telah layak dibaca. Sebuah artikel, akan sangat bagus jika sudah melewati proses editing bahasa. Jika itu berbahasa Indonesia, maka disunting oleh sarjana bahasa Indonesia. Jika berbahasa asing, akan sangat bagus jika mendapatkan suntingan dari sarjana atau native speaker dalam bidang ilmu yang serumpun. Tahapan publikasi bisa jadi berulang setelah disubmit ke editor jurnal. Setelah proses submit berlangsung, tidak mengirimkan artikel ke redaksi lain. Begitu pula perlu memperhatikan etika akademik lainnya (Shewan, \& Coats, 2010).

Pada tahapan awal menulis, semua informasi yang tersedia dimasukkan begitu saja. Hanya saja, ketika sudah sampai pada tahapan penyuntingan sudah perlu memperhatikan aspek tata bahasa dan juga pengecekan validitas referensi. Kelima tahapan tersebut akan mudah jika dilaksanakan dalam bentuk tim kecil. Sehingga ada kolega atau rekan sejawat yang menjadi mitra dalam proses penulisan ilmiah. Apalagi kalau bisa dalam ilmu yang sebidang. Tiga penelitian membuktikan bahwa dengan bekerja kolaboratif akan membantu meningkatkan kepekaan dan kepedulian anggota tim. Dengan catatan bahwa setiap anggota kelompok diberikan panduan kerja secara terstruktur sehingga memudahkan untuk pengecekan (Galegher, \& Kraut, 1994; Kraut, Galegher, Fish, \& Chalfonte, 1992; Lowry, \& Nunamaker, 2003). Proses penulisan akan diiringi dengan diskusi dan pada akhirnya akan menjadi sarana komunikasi akademik (Cronin, 1984; Garvey, 2014; Garvey, \& Griffith, 1971). Saat menulis dan menerbitkan ke sebuah terbitan ilmiah, menjadi kesempatan penulis untuk mendapatkan umpan balik dari kolega dan juga pengelola jurnal. Mereka akan memberi saran dalam penyempurnaan manuskrip. Akhirnya, proses menulis menjadi sebuah tahapan bukan saja dalam menulis, tetapi sejak mengidentifikasi ide dan menjadikannya sebagai sebuah issue ilmiah (Farid, 2017b).

\section{Format Penulisan Artikel}

Umumnya format penulisan artikel berisi antara lain: judul, abstrak, pendahuluan, metode penelitian, hasil, diskusi dan kesimpulan, serta daftar pustaka. Namun ada beberapa penambahan tergantung dari penyelenggara seminar atau pengelola jurnal. Umumnya mereka menyediakan template sebagai acuan bagi penulis untuk menulis. Maka, prinsip utama dan pertama dalam proses penulisan adalah author guidelines (Wekke, 2019b). Dalam kaitan ini, panduan penulisan tidak tunggal. Setiap jurnal ataupun setiap pelaksana konferensi memiliki panduan tersendiri sehingga penulis perlu memperhatikan panduan masing-masing sesuai dengan jurnal atau konferensi tujuan. Mengenali format dan panduan penulisan dilakukan di bagian awal supaya 
tidak mengulangi seluruh proses penulisan jikalau sudah dituliskan sejak awal. Sebuah jurnal bahkan secara khusus memberikan panduan penulisan terkait dengan pelaporan dan validasi penelitian (Cabrera-Nguyen, 2010). Struktur dasar artikel terdiri dari Introduction, Methods, Results, dan Discussion, kadang-kadang disingkat dengan IMRAD (Perneger, \& Hudelson, 2004).

\subsection{Judul}

Buatlah judul semenarik mungkin agar pembaca tertarik untuk membaca tulisan kita, namun perlu diingat bahwa judul merupakan gambaran tentang ide utama topik. Judul juga merupakan gambaran hasil sebuah artikel (Soler, 2007). Bisajadi judul tidak dituliskan paling awal melainkan bisa ditulis setelah menyelesaikan bagian hasil. Jika menggunakan penjadwalan 12 pekan, maka judul ditulis pada pekan kesepuluh dari proses penulisan artikel secara keseluruhan (Belcher, 2019). Judul perlu ditulis dengan minimal tiga kriteria, yaitu singkat, menarik perhatian, dan kehati-hatian dalam pemilihan kata yang menggambarkan hasil penelitian (Day, 1998).

Contoh:

\section{Fatique of Metal Foams}

lebih baik bila dituliskan

The Mechnical Response of Cymat and Alporas Metallic Foams to Uni-axial Cyclic Loading (Ashby, 2005)

\subsection{Abstrak}

Abstrak merupakan representasi dari artikel yang terdiri dari tujuan, metode, hasil, kesimpulan dan batasan penelitian kita. Usahakan mengikuti aturan soal jumlah kata dan diakhiri dengan menuliskan kata kunci atau key words yang terdiri dari 3 - 5 kata (Ashby, 2005). Harris (2006) mengemukakan tiga langkah dalam proses menulis abstrak dengan urutan sebagai berikut: pertama, mengidentifikasi perbedaan antara menulis dengan menulis akademik. Kedua, komunikasi akademik dengan semakin sederhana akan semakin bagus. Sekaligus memperhatikan aturan umum dalam proses penulisan sains (Weinberger, Evans, \& Allesina, 2015). Terakhir, proses menulis diselesaikan, sebelum disunting. Urutan penulisan abstract dimulai dari pendahuluan, dilanjutkan dengan metode, dan hasil. Terakhir, kesimpulan perlu dinyatakan secara tertulis (Kaplan, Cantor, Hagstrom, Kamhi-Stein, Shiotani, \& Zimmerman, 1994). Namun, keempat dari unsur abstract tersebut bukan merupakan pengulangan dari tulisan dalam artikel 
yang sudah ada sebelumnya.

\subsection{Pendahuluan}

Dalam mengurai pendahuluan, biasanya penulis memulai dengan mengemukakan permasalahan secara jelas. Selanjutnya mengemukakan hasil penelitian sebelumnya yang akan digunakan sebagai referensi untuk melakukan penelitian (Swales, \& Najjar, 1987). Selain itu, menampilkan data pendukung yang update dan yang terpenting mengungkapkan apa yang hal baru (novelty) yang ditawarkan penulis. Dalam bagian pendahuluan ini juga sejak awal dikemukakan masalah penelitian yang akan dikaji (Stapa, Maasum, \& Aziz, 2014). Maka, sebuah masalah merupakan jarak antara praktik dan teori. Dengan demikian, pendahuluan berusaha untuk mendekatkan jarak keduanya (Chafouleas, \& Riley-Tillman, 2005).

\subsection{Studi Literatur}

Walau tidak dituliskan secara khusus dalam bentuk sub-judul, studi literatur juga dikenali dengan nama lain state-of-the-art. Pada bagian ini penulis menguraikan teori atau penelitian yang relevan dengan topik yang dibahas. Sehingga akan memudahkan bagi penulis dalam mendukung argumen untuk menentukan variabel dan model penelitian yang dikembangkan. Penulisan kajian literatur untuk menjadi penanda bahwa artikel yang disajikan, mengajukan sebuah pengetahuan baru dan bukan pengulangan (Torraco, 2005).

Misalnya pada artikel Farid \& Day (2016) dengan topik: "konstruksi model service innovation SMEs pada industri otomotif", membagi studi literaturnya menjadi: concept of service innovation, service typology, SMEs in Automotive Industries, model of innovation, innovation degree and type dan conceptual model of service innovation for SMEs industries. Banyaknya sub topik yang ditulis sangat tergantung sejauh mana penulis ingin menguraikan pentingnya data, teori, model dan penelitian sebelumnya. Semuanya dituliskan untuk menggambarkan bagaimana publikasi sebelumnya yang terkait dengan topik yang sementara dituliskan. Kajian literatur yang ditempatkan dalam sebuah laporan penelitian atau skripsi/tesis/disertasi kemudian disintesa dalam dua atau paragraf saja. Penulisan sintesa ini juga disebut dengan istilah state-of-the-art (Kellog, 2006). State of the art menggambarkan kebaruan penelitian dan konteks yang berbeda dengan penerbitan yang sudah ada sebelumnya. Bisa jadi artikel yang ditulis tidak baru sama sekali, tetapi kelanjutan dari publikasi sebelumnya. 


\subsection{Metode Penelitian}

Berikutnya metode penelitian, metode yang akan kita gunakan untuk menyelesaikan masalah. Jenisnya bermacam-macam, antara lain: review study, studi kasus, eksprimen dan lainnya. Pendekatan penelitian kualitatif secara khusus perlu mengemukakan tipikal metode yang digunakan (Muhadjir, 1996; Creswell, \& Poth, 2017). Pilihan metode yang sesuai untuk menyelesaikan masalah penelitian dengan mempertimbangkan sumber daya dan waktu yang dimiliki peneliti. Termasuk kesesuaian antara tujuan penelitian dan keeratan dengan bagaimana menjawab persoalan yang diajukan. Sementara dalam penelitian dengan pendekatan kuantitatif, analisis dan software yang digunakan cukup dijelaskan secara singkat. Bahkan tidak perlu mengemukakan rumus yang digunakan. Desain penelitian dijelaskan dengan detail namun dibatasi dengan dalam narasi paragraf. Termasuk menjelaskan posisi validitas dan reabilitas instrumen penelitian yang digunakan (Creswell, 2017). Selanjutnya dideskripsikan dan diterangkan terkait dengan dua dimensi yaitu tujuan penelitian dan waktu pengumpulan data (Maxim, 1999; Johnson, 2001). Metode yang digunakan tidak bisa bias (Azevedo, Canário-Almeida, Fonseca, Costa-Pereira, Winck, \& Hespanhol, 2011; ), ini akan memengaruhi hasil penelitian yang diperoleh. Serta upaya yang dilakukan peneliti untuk melakukan triangulasi data dalam pengecekan keabsahan data yang diperoleh.

Contoh: metode eksprimen, jelaskan peralatan, bahan baku dan metode yang digunakan. Menjelaskan secara spesifik metode yang digunakan, termasuk informasi yang detail bagaimana metode yang digunakan dalam pengumpulan dan pengolahan data (Ashby, 2005).

\subsection{Hasil}

Menampilkan hasil pengolahan data yang menunjukkan apakah hubungan antar variabel signifikan dan model yang diteliti secara utuh tanpa memberikan opini dan analisa. Hasil yang dikemukakan merupakan data yang didapatkan dari lapangan sesuai dengan pertanyaan penelitian yang diajukan sejak awal. Penulisan hasil merupakan data yang sudah dianalisis, bukan data yang masih apa adanya setelah pengolahan dari sumber atau subyek penelitian (Pyrczak, 2016). Data yang disajikan sepenuhnya merupakan kumpulan dari data yang diperoleh secara empiris (Garson, 2001). Pendapat atau opini penulis belum dikemukakan dalam bagian ini. Sehingga semua data yang tersaji dapat dicek kembali oleh pembaca. Kotz \& Cals (2013) mengemukakan daftar pengecekan untuk penulisan hasil sebagai berikut 1) ditulis dengan kalimat lampau; 2) menyajikan data tanpa interpretasi sama sekali; 3) jika memungkinkan terdapat tabel 
dan grafik dan dijelaskan pada bagian-bagian tertentu yang penting; 4) bagian hasil perlu mengemukakan analisis utama. Keempat unsur ini ditulis dengan pola berurutan sebagaimana dalam pertanyaan penelitian. Pada subjudul hasil ini merupakan jawaban dari pertanyaan yang diajukan atau tujuan penulisan artikel (Kotz, \& Cals, 2013). Bagian ini perlu tetap relevan dengan bagian-bagian yang ada sebelumnya, dengan menjawab apa yang dihasilkan dari penelitian (Bahadoran, Mirmiran, Zadeh-Vakili, Hosseinpanah, \& Ghasemi, 2019). Tetapi bukan interpretasi atas data yang sudah dikemukakan.

\subsection{Pembahasan atau Diskusi}

Pada bagian ini, penulis ingin memberikan penjelasan untuk membandingkan hasil dari eksprimen yang telah dilakukan dengan teori dan penelitian sebelumnya. Selanjutnya, pada bagian diskusi memberikan argumen terhadap data yang telah ditampilkan pada bagian hasil. Bagian ini merupakan kesempatan bagi penulis untuk menyampaikan pemaknaan terhadap hasil yang sudah disampaikan pada bagian sebelumnya. Sekaligus, penulis akan memberikan konteks hasil sebagai temuan yang baru (Cals, \& Kotz, 2013). Unsur yang perlu ada dalam bagian ini adalah arti data menurut penulis (Hess, 2004). Sekaligus dibandingkan dengan publikasi sebelumnya, baik dalam kesamaan maupun perbedaan. Ketika menulis interpretasi dengan merujuk artikel tetap perlu memperhatikan relevansi (Jenicek, 2006).

\subsection{Kesimpulan dan Batasan}

Bagian akhir sebuah tulisan pada kesimpulan yang menjadi penutup atau menjawab pertanyaan yang diajukan sejak awal. Kesimpulan merupakan kalimat yang dituliskan untuk menjawab masalah penelitian dan menguraikan temuan penting dari penelitian yang dilakukan. Sebagai sebuah sistem, penulisan perlu ditulis secara analitik, kritis, dan logis (Smyth, 2004). Tidak memungkinkan adanya suspend and surprise dalam proses penulisan. Tetapi struktur dan alur penulisan perlu mengikut kaedah ilmiah. Bukti-bukti sudah diajukan, fakta sudah dikemukakan, maka selanjutnya dari keseluruhan maklumat tersebut, dieprlukan kesimpulan yang menjadi rangkuman dari keseluruhan informasi (Babcock, \& Thonus, 2018). Sebagai penutup dari tulisan maklumat yang dituliskan tidak lagi dalam bentuk kalimat general tetapi semakin spesifik (Fulwiler, 2007). Pada poin batasan, penulis mesti mengungkapkan kelemahan penelitiannya, sebagai bahan evaluasi dan rekomendasi bagi peneliti selanjutnya. Penelitian terikat pada factor tertentu dan kondisi tertentu. Maklumat mengenai ini dikemukakan penulis 
bukan sebagai kelemahan, justru menjadi informasi bahwa penelitian yang dilaksanakan tidak dapat menjelaskan fonomena secara keseluruhan (Connelly, 2013).

\subsection{Daftar Pustaka}

Penulisan referensi yang digunakan pada artikel hendaknya mengacu pada panduan yang telah ditetapkan oleh penyelenggara seminar atau pengelola jurnal. Semua referensi yang digunakan wajib tersedia dalam bentuk daring. Pelbagai gaya penulisan yang perlu diperhatikan diantaranya APA (American Phychological Association, 2010), Harvard Referencing Standards (Dwyer, 1995), Modern Language Association of America (Gibaldi, \& Achtert, 2003). Chicago Style (Turabian, 2013), dan Vancouver Style (Huth, 1981). Setiap madzhab penulisan itu memiliki aturan tersendiri. Sebagai contoh:

1) APA

Wang, C. N., Day, J. D., \& Farid, M. (2019). Service Innovation Model of the Automobile Service Industry. Applied Sciences, 9(12), 2403.

\section{2) Harvard}

Wang, C.N., Day, J.D. and Farid, M., 2019. Service Innovation Model of the Automobile Service Industry. Applied Sciences, 9(12), p.2403.

\section{3) MLA}

Wang, Chia-Nan, Jen-Der Day, and Muhammad Farid. "Service Innovation Model of the Automobile Service Industry." Applied Sciences 9.12 (2019): 2403.

\section{4) Chicago}

Wang, Chia-Nan, Jen-Der Day, and Muhammad Farid. "Service Innovation Model of the Automobile Service Industry." Applied Sciences 9, no. 12 (2019): 2403.

\section{5) Vancouver}

Wang CN, Day JD, Farid M. Service Innovation Model of the Automobile Service Industry. Applied Sciences. 2019 Jan;9(12):2403.

Untuk memudahkan penulisan daftar pustaka mengikut kepada gaya masing-masing madzhab tersebut, maka penggunaan fasilitas perangkat lunak (software) akan sangat membantu 
sehingga ketepatan dan kecermatan dapat tercapai. Dengan bantuan teknologi informasi itu akan menjadi instrumen dalam produktivitas karya ilmiah (Nur, Sabara, \& Wekke, 2018). Beberapa pilihan diantaranya Zotero, Mendeley, dan Endnote. Dalam penulisan daftar pustaka prinsip yang perlu diperhatikan yaitu keakuratan, kelengkapan, dan keseragaman keseluruhan informasi yang tersaji dalam daftar pustaka. Satu hal lagi, semua informasi yang dirujuk dalam batang tubuh artikel, wujud di daftar pustaka. Sebaliknya, apapun yang tersenarai dalam daftar pustaka merupakan pendamping dari narasi kalimat-kalimat yang ada dalam bagian artikel sebelumnya.

\section{Publikasi Artikel Ilmiah}

Setelah manuskrip siap, langkah berikutnya persiapan untuk publikasi. Terdapat dua peluang yang dapat dilakukan penulis. 1) Sejak awal disiapkan bahwa tulisan saya akan dipublikasikan untuk seminar atau jurnal. 2) Memilih berdasarkan peluang, apakah artikel ini bisa memenuhi kriteria jurnal atau cukup seminar saja.

Sebagai penulis, tentunya juga perlu memperhatikan syarat yang ditetapkan oleh pihak kampus. Misalnya, untuk menyelesaikan studi pada program magister dengan cukup mengikuti seminar internasional dan pada program doktoral harus mengikuti seminar internasional minimal sekali dan mempublikasikan artikel pada minimal dua jurnal dengan syarat tertentu. Masing-masing kampus memilik standar dam kriteria yang tersendiri. Maka mengecek kemutakhiran kebijakan kampus masing-masing direkomendasikan.

\subsection{Seminar (Conference)}

Mengikuti international conference menjadi sebuah kesempatan bagi penulis, apatah lagi pelaksanaannya di luar negeri. Ini akan membantu untuk mendapatkan maklumat terkini. Selain merasakan atmosfir internasional, kita juga bisa langsung bertemu dengan peneliti dari berbagai negara, menambah jaringan dan tentunya bisa berkunjung ke perguruan tinggi di kota tersebut. Namun sebelum menentukan seminar yang akan diikuti hendaknya kita memperhatikan beberapa faktor antara lain: tujuan, penyelenggara, relevansi dengan artikel dan peluang publikasi jurnal.

Mencari informasi informasi sebanyak mungkin melalui penelusuran internet atau pengalaman kolega yang telah mengikuti international conference untuk memastikan reputasi penyelenggara. Hal ini untuk mencegah kita mengikuti seminar abal-abal atau predator, selain itu tentunya kita memperhatikan peluang artikel yang dikirim dapat dipublikasikan pada jurnal ilmiah. Bila artikel kita memenuhi syarat sesuai ketentuan dari penyelenggara. Beberapa 
alternatif seminar yang prosidingnya diterbitkan melalui IEEE/IEEM dengan prosiding berISBN. Sekalipun Idrus (2019) menyatakan bahwa penerbitan makalah di prosiding merupakan "selemah-lemahnya publikasi".

Perlu juga dipertimbangkan terkait dengan waktu dan sumber daya yang kita miliki. Apabila waktu pelaksanaannya masih jauh, bila menunggu akan menghambat proses penelitian berikutnya. Padahal kita akan menggunakan referensi tersebut pada penelitian berikutnya. Perihal sumber daya, harus mempertimbangkan biaya yang dibutuhkan untuk pendaftaran, transportasi dan akomodasi selama mengikuti seminar. Ada seminar atau konferensi yang memberikan kesempatan untuk presentasi dengan cara virtual. Ini akan mengurangi komponen pembiayaan berupa tiket dan akomodasi.

Terdapat pula kampus yang mensyaratkan setelah penyelesaian studi pada program magister sesuai dengan arahan pembimbing maka dianjurkan mengikuti seminar nasional dengan mengirimkan artikel dari penyederhanaan tesis. Berdasarkan ide tersebut akhirnya saya membuatnya menjadi dua artikel, pertama Farid dan Lawalata (2010) pada seminar nasional Teknik Industri di Bandung. Kedua, Farid dan Wiratmadja (2011) pada seminar nasional Teknik Industri di Medan.

Saat melanjutkan studi di program doktoral, prosesnya menjadi terbalik. Sambil menyusun karya tulis yang diwajibkan. Pembimbing menganjurkan untuk menulis artikel secara bertahap dengan menyesuaikan dengan road map research. Sebagai langkah awal dengan mengirimkan artikel Farid \& Day (2016) seminar internasional yang diselenggarakan di Kyoto Jepang dimana artikel ini diterima untuk presentasi dan selanjutnya artikel Day \& Farid (2016) pada seminar internasional yang diselenggarakan di Semarang dipresentasikan oleh pembimbing. Kedua makalah tersebut merupakan bagian dari penelitian disertasi.

Terdapat pula pola penerbitan dengan didahului dari seminar. Diawali dari presentasi seminar yang awalnya berjudul "Tradisi Keislaman di Perguruan Tinggi Dalam Pendidikan Spiritual Bagi Mahasiswa: Studi Kasus Pendidikan Tinggi Islam Minoritas Muslim" (Hermawanto, Ashrori, \& Wekke, 2016). Setelah melalui penyuntingan dan penulisan ulang, manuskrip kemudian dikirim ke editor jurnal dan terbit dengan judul "Keberagamaan Mahasiswa di Perguruan Tinggi Wilayah Minoritas Muslim” (Wekke, Hermawanto, \& Ashrori, 2016). Ada proses review dan juga editing dari yang asalnya presentasi di seminar kemudian dikonversi menjadi artikel jurnal. 


\subsection{Journal}

Mengirimkan karya ke editor jurnal perlu memperhatikan beberapa aspek, antara lain: kesesuaian dengan topik, reputasi jurnal, dan memenuhi persyaratan stake holder. Kesesuaian antara tema artikel dengan topik jurnal yang dituju, perlu menjadi perhatian utama. Hal ini penting agar tidak terjadi penolakan artikel yang telah kita submit (serahkan) pada kesempatan pertama. Karena proses dari submit hingga adanya informasi bahwa artikel diterima atau ditolak, membutuhkan waktu yang bergantung kepada ritme kerja masing-masing editor. Tidak ada waktu yang sama antar setiap artikel dalam melalui proses penerbitan. Catatan penting sebuah artikel bahwa tidak bisa terbit secara tiba-tiba, melainkan ada tahapan yang akan dilalui dan semuanya itu terikat pada waktu. Jika sebuah artikel dikirim hanya untuk mendapatkan penolakan sebab ketidaksesuaian aim and scope artikel yang terkirim dengan jurnal, merupakan kesia-siaan. Sementara waktu studi yang terbatas atau waktu untuk pelaporan kinerja penelitian yang juga terbatas.

Mengidentifikasi reputasi jurnal penting diketahui agar menghindari artikel yang telah dipublikasikan tidak dapat digunakan sebagai standar kualifikasi. Setiap tahun pihak pengelola $\mathrm{SCI} / \mathrm{EI} / \mathrm{Scopus}$ akan mengumumkan daftar jurnal yang masuk dalam kualifikasi index mereka. Sebagai contoh pada program studi Industrial Engineering and Management (IEM) NKUAS untuk mahasiswa mulai angkatan 2015 diwajibkan publikasi minimal dua artikel pada jurnal yang terindex Science Citation Index (SCI) dan atau Engineering Index (EI). Bisa saja setiap perguruan tinggi memiliki kriteria yang berbeda-beda. Sehingga tidak bisa diseragamkan antara satu institusi dengan yang lain. Sebagai contoh Pascasarjana Universitas Padjajaran, Bandung yang mewajibkan mahasiswa untuk menerbitkan bagian disertasi. Adapun kriteria jurnal perlu didiskusikan antara mahasiswa dengan promotor. Persetujuan promotor terhadap jurnal yang menjadi tujuan pengiriman perlu diperhatikan sebab ini merupakan bagian dari tahapan proses perkuliahan.

Sementara bagi dosen, dengan terbitnya Permenristekdikti 20/2017 menjadi era baru publikasi ilmiah Indonesia (Irawan, Abraham, Multazam, M. T., Rachmi, Mulyaningsih, Viridi, \& Puradimaja, 2018). Peraturan tersebut mengemukakan kriteria publikasi internasional dengan ketentuan sebagai berikut: 1) jurnal internasional, terindex pada ISI Web of Science (Thomson Reuters), atau terdapat dalam display Scimago Journal and Country Rank dengan Q4 (quartile empat) atau terindeks di Microsoft Academic Search. 2) jurnal internasional bereputasi, terindex Scopus dengan Q3 (quartile 3). Selain itu, apabila prosiding seminar internasional terindex basis data internasional seperti Web of Science, Scopus; maka dinilai sama dengan jurnal internasional. 
Panduan ini akan sangat dinamis dan berubah seiring dengan adanya penyesuaian dari masing-masing institusi pengindeks. Sebuah jurnal yang sudah terindeks pada lembaga pengindeks, bisa saja dikeluarkan atau tidak lagi terideks. Bahkan sebuah paper dikeluarkan dari pangkalan data. Pengecekan dapat menggunakan laman web yaitu www.scimagojr.com, www.scopus.com, dan http://mjl.clarivate.com.

Sehingga bagi mahasiswa program doktoral diharapkan selain memenuhi syarat yang ditetapkan oleh pihak kampus tempat studinya, juga memperhatikan yang disyaratkan kemristekdikti atau lembaga penyandang dana penelitian. Agar artikel yang dipublikasikan selain memenuhi syarat penyelesaian studi juga dapat digunakan untuk keperluan lain sesuai dengan kondisi perguruan tinggi masing-masing.

Bagaimana dengan peneliti pemula? Tahapan awal dapat dimulai mengirimkan artikel pada jurnal internasional dengan rangking dan impact factor kualifikasi Q4 atau dengan nilai impact factors berkisar antara 0.01 - 1.0. Harapan sebagai penulis, artikel ilmiah dapat terpublikasi dan yang penting telah memenuhi syarat yang disyaratkan stake holder.

\section{Plagiarism}

Mengutip sebuah karya orang lain, haruslah dengan menggunakan kaidah yang ditetapkan. Jangan sampai penulis mengklaim bahwa apa yang dituliskan itu merupakan karya kita. Kejujuran merupakan kunci utama dalam proses pengutipan karya. Apabila ingin menuliskan kembali ide yang telah ditulis sebelumnya, maka kita harus menuliskan sesuai dengan kaidah yang berlaku. Bila tidak mengikuti prosedur maka kita akan dikenakan dengan self plagiarism. Proses pengecekan dapat dilakukan dengan melihat registrasi. Jika sebuah karya sudah mendapatkan ISSN atau ISBN, maka karya itu tidak bisa dipublikasikan kembali kecuali dengan paraphrase.

Mencegah terjadinya plagiarism dan akan berdampak ditolaknya artikel yang diajukan. Maka sebelum mengirimkan artikel gunakanlah bantuan tools untuk mendeteksi apakah tulisan tersebut memiliki kesamaan dengan tulisan orang lain. Beberapa software yang disediakan oleh pihak kampus atau bisa diunduh secara gratis dapat digunakan untuk mendeteksi similarity (kesamaan) tulisan, diantaranya Turnitin. Alat ini dapat membantu mengidentifikasi kalimat yang kita gunakan dan mengukur persentase kesamaannya. Setelah melakukan revisi, lakukan pengecekan kembali. Bila hasilnya $<20 \%$, maka artikel anda sudah layak dikirim ke penerbit. Namun perlu diperhatikan bahwa kesamaan berbeda dengan plagiarism. Beberapa hal harus 
memiliki kesamaan seperti penulisan UU atau aturan, begitu juga dalam penulisan sosial seperti aturan dan juga penulisan ayat Alquran. Secara khusus, jikalau tidak terkait dengan kajian Alquran, maka penulisan ayat tidak diperlukan sama sekali.

\section{Penutup}

Apakah kita menulis karena untuk memenuhi persyaratan sebuah "kelulusan" ataukah menjadikannya sebagai sebuah "passion". Jika hanya menulis untuk kenaikan pangkat semata, maka setelah naik pangkat proses menulis berhenti juga. Namun untuk memenuhi "panggilan jiwa”, maka rintangan dan halangan apapun juga akan diabaikan.

Menulis artikel ilmiah membutuhkan proses yang panjang dari menemukan ide hingga publikasi. Proses ini tidak dilakukan secara instan, membutuhkan tahapan, kesungguhan dan konsistensi sebagai penulis. Maka, jika penulis mengajukan pertanyaan bukan dengan kalimat "kapan terbit?" tetapi pertanyaan yang lebih tepat dengan kalimat "apa yang harus saya perbaiki?". Dengan demikian, sebuah artikel begitu berada di tangan editor akan mengikuti proses penerbitan dan tidak bisa langsung terbit melainkan mengikuti tahapan yang juga editor terikat didalamnya. Artikel tidak bisa terbit begitu saja sebelum mengikuti proses yang dipersyaratkan. Termasuk, artikel terikat dengan jadwal terbit jurnal.

\section{Daftar Pustaka}

American Psychological Association. (2010). Publication manual of the American psychological association. Washington DC: American Psychological Association.

Ashby, M. (2005). How to write a paper. Cambridge: Engineering Department, University of Cambridge.

Azevedo, L. F., Canário-Almeida, F., Fonseca, J. A., Costa-Pereira, A., Winck, J. C., \& Hespanhol, V. (2011). How to write a scientific paper-Writing the methods section. Revista portuguesa de pneumologia, 17(5), 232-238.

Babcock, R. D., \& Thonus, T. (2018). Researching the writing center: Towards an evidence-based practice. Pieterlan: Peter Lang International Academic Publishers.

Bahadoran, Z., Mirmiran, P., Zadeh-Vakili, A., Hosseinpanah, F., \& Ghasemi, A. (2019). The Principles of Biomedical Scientific Writing: Results. International Journal of Endocrinology and Metabolism, 17(2).

Belcher, W. L. (2019). Writing your journal article in twelve weeks: A guide to academic publishing success. Chicago: University of Chicago Press. 
Cabrera-Nguyen, P. (2010). Author guidelines for reporting scale development and validation results in the Journal of the Society for Social Work and Research. Journal of the Society for Social Work and Research, 1(2), 99-103.

Cals, J. W., \& Kotz, D. (2013). Effective writing and publishing scientific papers, part VI: discussion. Journal of clinical epidemiology, 66(10), 1064.

Chafouleas, S. M., \& Riley-Tillman, T. C. (2005). Accepting the gap: An introduction to the special issue on bridging research and practice. Psychology in the Schools, 42(5), 455-458.

Chase, J. M. (1970). Normative criteria for scientific publication. The American Sociologist, 262-265.

Clemens, R., \& Graham, T. (2007). Introduction to manuscript studies. Ithaca, NY: Cornell University Press.

Connelly, L. M. (2013). Limitation section. Medsurg Nursing, 22(5), 325-327.

Creswell, J. D. (2017). Research design: Qualitative, quantitative, and mixed methods approaches. Washington, USA: Sage publications.

Creswell, J. W., \& Poth, C. N. (2017). Qualitative inquiry and research design: Choosing among five approaches. Washingto, USA: Sage publications.

Cronin, B. (1984). The citation process: The role and significance of citations in scientific communication. London: T. Graham.

Day, J. D., \& Farid, M. (2016). Stepwise Strategy for Taiwan's Semiconductor Industry as Core Technology. Proceedings of ICBEST, Semarang, Indonesia, August 24, 2016, 1-8.

Day, R. A. (1998). How to write and publish scientific papers. Memórias do Instituto Oswaldo Cruz, 93(3).

Dwyer, M. (1995). A guide to the Harvard referencing system. British journal of Nursing, 4(10), 599-602.

Fara, P. (1999). Catch a falling apple: Isaac Newton and myths of genius. Endeavour, 23(4), 167-170.

Farid M., \& Day, J. D. (2016). Constructing Service Innovation Model for Automotive Service Industries: A Case Study of Auto Repair Motorcycle in Makassar City. Proceedings of ICIMIE, Kyoto, Japan, November 10-11, 2016, 812-816.

Farid, M. (2017a). Membumikan Ide, Ukirlah Sejarah Di Masamu. Tabloid Profesi, 218, 14.

Farid, M. (2017b). Menulis Artikel Ilmiah: Proses Menemukan Ide Hingga Publikasi. Seminar Penulisan Artikel Ilmiah, Perhimpunan Pelajar Indonesia (PPI) NPUST, Taiwan, NPUST Campus, Pingtung, 28 Oktober 2017.

Farid, M., \& Lawalata, V. (2010). Pengaruh Kualitas Jasa Terhadap Kepuasan dan Minat Perilaku Konsumen: Studi kasus Pada Bengkel Mobil Resmi. Prosiding Seminar Nasional Teknik Industri, Bandung, 24 November 2010, F61-F68.

Farid, M., \& Wiratmadja, I. I. (2011). Pengembangan Model Service Quality Industri Jasa Otomotif. Prosiding Seminar Nasional Teknik Industri dan Kongres BKSTI VI. Medan, 5-6 
Oktober 2011, 148-156.

Fulwiler, B. R. (2007). Writing in science. Portsmouth, NH: Heinemann.

Galegher, J., \& Kraut, R. E. (1994). Computer-mediated communication for intellectual teamwork: An experiment in group writing. Information systems research, 5(2), 110-138.

Garson, G. D. (2001). Guide to writing empirical papers, theses, and dissertations. CRC Press.

Garvey, W. D. (2014). Communication: the essence of science: facilitating information exchange among librarians, scientists, engineers and students. Elsevier.

Garvey, W. D., \& Griffith, B. C. (1971). Scientific communication: Its role in the conduct of research and creation of knowledge. American psychologist, 26(4), 349.

Gibaldi, J., \& Achtert, W. S. (2003). MLA handbook for writers of research papers. New York: Modern Language Association of America.

Gleick, J., \& Alexanderson, G. L. (2005). Isaac Newton. The Mathematical Intelligencer, 27(3), 74-76.

Gosden, H. (1995). Success in research article writing and revision: A social-constructionist perspective. English for Specific Purposes, 14(1), 37-57.

Harris, M. J. (2006). Three steps to teaching abstract and critique writing. International Journal of Teaching and Learning in Higher Education, 17(2), 136-146.

Hermawanto, A., Ashrori, M., \& Wekke, I. S. (2016). Tradisi Keislaman di Perguruan Tinggi Dalam Pendidikan Spiritual Bagi Mahasiswa: Studi Kasus Pendidikan Tinggi Islam Minoritas Muslim. Prosiding Seminar Nasional Integrasi Keilmuan, Program Pasca Sarjana Universitas Islam Negeri Sultan Syarif Kasim Pekanbaru, 21 Mei 2016.

Hess, D. R. (2004). How to write an effective discussion. Respiratory care, 49(10), 1238-1241.

Huth, E. (1981). Style Matters: Manuscript requirements: the advance from Vancouver. $\mathrm{Br} \mathrm{Med} J$ (Clin Res Ed), 282(6257), 55-56.

Irawan, D. E., Abraham, J., Multazam, M. T., Rachmi, C. N., Mulyaningsih, I., Viridi, S., ... \& Puradimaja, D. J. (2018). Era baru publikasi di Indonesia: status jurnal open access di Directory of Open Access Journal (DOAJ). Berkala Ilmu Perpustakaan dan Informasi, 14(2), 133-147.

Jenicek, M. (2006). How to read, understand, and write'Discussion'sections in medical articles. An exercise in critical thinking. Medical Science Monitor, 12(6), SR28-SR36.

Jensen Schau, H., \& Muñiz Jr, A. M. (2006). A tale of tales: the Apple Newton narratives. Journal of Strategic Marketing, 14(1), 19-33.

Johnson, B. (2001). Toward a new classification of nonexperimental quantitative research. Educational Researcher, 30(2), 3-13.

Kaplan, R. B., Cantor, S., Hagstrom, C., Kamhi-Stein, L. D., Shiotani, Y., \& Zimmerman, C. B. (1994). On abstract writing. Text-Interdisciplinary Journal for the Study of Discourse, 14(3), 401-426. 
Kellogg, R. T. (1990). Effectiveness of prewriting strategies as a function of task demands. The American Journal of Psychology, 327-342.

Kellogg, R. T. (2006). Professional Writing Expertise. In K. A. Ericsson, N. Charness, P. J. Feltovich, \& R. R. Hoffman (Eds.), The Cambridge handbook of expertise and expert performance (pp. 389-402). New York, NY, US: Cambridge University Press.

Kotz, D., \& Cals, J. W. (2013). Effective writing and publishing scientific papers, part V: results. Journal of clinical epidemiology, 66(9), 945.

Kraut, R., Galegher, J., Fish, R., \& Chalfonte, B. (1992). Task requirements and media choice in collaborative writing. Human-Computer Interaction, 7(4), 375-407.

Laplante, P. A. (2018). Technical Writing: A Practical Guide for Engineers, Scientists, and Nontechnical Professionals. Florida: CRC Press.

Lester, J. D., \& Lester, J. D. (2012). Writing research papers: A complete guide. New York: Pearson.

Lindsey, D. (1978). The scientific publication system in social science. San Francisco: Jossey-Bass.

Lowry, P. B., \& Nunamaker, J. F. (2003). Using Internet-based, distributed collaborative writing tools to improve coordination and group awareness in writing teams. IEEE Transactions on Professional Communication, 46(4), 277-297.

Maxim, P. S. (1999). Quantitative research methods in the social sciences. New York: Oxford University Press.

McKie, D., \& De Beer, G. R. (1951). Newton's apple. Notes and Records of the Royal society of London, 9(1), 46-54.

Muhadjir, N. (1996). Metodologi penelitian kualitatif. Yogyakarta: Rake Sarasin.

Nur, T., Sabara, H. Z., \& Wekke, I. S. (2018). Teknik Menulis Karya Ilmiah: Dengan 8 Senjata Aplikasi Pendukung Produktivitas Riset. Yogyakarta: Deepublish.

Perneger, T. V., \& Hudelson, P. M. (2004). Writing a research article: advice to beginners. International journal for quality in health care, 16(3), 191-192.

Pyrczak, F. (2016). Writing empirical research reports: A basic guide for students of the social and behavioral sciences. London: Routledge.

Rohman, D. G. (1965). Pre-writing the stage of discovery in the writing process. College composition and communication, 16(2), 106-112.

Smyth, T. R. (2004). Thinking and Writing. The Principles of Writing in Psychology. London: Red Globe Press.

Soler, V. (2007). Writing titles in science: An exploratory study. English for specific purposes, 26(1), 90-102.

Stapa, S. H., Maasum, T. N. R. T. M., \& Aziz, M. S. A. (2014). Identifying problems in writing thesis introductions in research methodology class. Procedia-Social and behavioral sciences, 112, 497-502. 
Swales, J., \& Najjar, H. (1987). The writing of research article introductions. Written communication, 4(2), 175-191.

Toer, P. A. (1990). Rumah Kaca. Kuala Lumpur: Wira Karya.

Torraco, R. J. (2005). Writing integrative literature reviews: Guidelines and examples. Human resource development review, 4(3), 356-367.

Turabian, K. L. (2013). A manual for writers of research papers, theses, and dissertations: Chicago style for students and researchers. Chicago: University of Chicago Press.

Weinberger, C. J., Evans, J. A., \& Allesina, S. (2015). Ten Simple (Empirical) Rules for Writing Science. PLoS Comput Biol, 11(4): e1004205. https://doi.org/10.1371/journal.pcbi.

Wekke, I. S. (2019a). Akselerasi Pembelajaran Pascasarjana Dalam Pengembangan Tradisi Keilmuan. https://doi.org/10.31227/osf.io/fw5r6.

Wekke, I. S. (2019b). Menulis Artikel Jurnal. Pelatihan Karya Tulis Ilmiah \& Publikasi Jurnal Ilmiah, Pascasarjana Universitas Islam Negeri Alauddin Makassar, Sabtu, 20 Juli 2019. https://doi.org/10.31227/osf.io/p4s3c.

Wekke, I. S., Hermawanto, A., \& Ashrori, M. (2016). Keberagamaan Mahasiswa di Perguruan Tinggi Wilayah Minoritas Muslim. Ulul Albab, 17(2), 135.

Idrus, N. I. (2019). Scopus. Harian Fajar Makassar, 5. 